\title{
Corals exhibit distinct patterns of microbial reorganisation to thrive in an extreme inshore environment
}

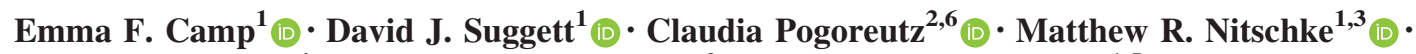 \\ Fanny Houlbreque $^{4}$ (D) Benjamin C. C. Hume $^{2}$ (D) Stephanie G. Gardner ${ }^{1,5}$ (D) \\ Marco Zampighi ${ }^{4} \cdot$ Riccardo Rodolfo-Metalpa $^{4}$ (D) Christian R. Voolstra ${ }^{2,6}$ (D)
}

\begin{abstract}
Climate change threatens the survival of scleractinian coral from exposure to concurrent ocean warming, acidification and deoxygenation; how corals can potentially adapt to this trio of stressors is currently unknown. This study investigates three coral species (Acropora muricata, Acropora pulchra and Porites lutea) dominant in an extreme mangrove lagoon (Bouraké, New Caledonia) where abiotic conditions exceed those predicted for many reef sites over the next 100 years under climate change and compared them to
\end{abstract}

Topic Editor Carly Kenkel conspecifics from an environmentally more benign reef habitat. We studied holobiont physiology as well as plasticity in coral-associated microorganisms (Symbiodiniaceae and bacteria) through ITS2 and 16S rRNA sequencing, respectively. We hypothesised that differences in coral-associated microorganisms (Symbiodiniaceae and bacteria) between the lagoonal and adjacent reef habitats may support coral host productivity and ultimately the ability of corals to live in extreme environments. In the lagoon, all coral species exhibited a metabolic adjustment of reduced photosynthesisto-respiration ratios $(\mathrm{P} / \mathrm{R})$, but this was accompanied by highly divergent coral host-specific microbial associations. This was substantiated by the absence of shared ITS2-type profiles (proxies for Symbiodiniaceae genotypes). We

\section{Christian R. Voolstra}

christian.voolstra@uni-konstanz.de

emma.camp@uts.edu.au

David J. Suggett

David.suggett@uts.edu.au

Claudia Pogoreutz

claudia.pogoreutz@uni-konstanz.de

Matthew R. Nitschke

Matthew.Nitschke@uts.edu.au

Fanny Houlbreque

fanny.houlbreque@ird.fr

Benjamin C. C. Hume

Benjamin.hume@kaust.edu.sa

Stephanie G. Gardner

s.gardner@unsw.edu.au

Marco Zampighi

zampa1789@gmail.com

Riccardo Rodolfo-Metalpa

Riccardo.rodolfo-metalpa@ird.fr
Climate Change Cluster, University of Technology Sydney, Ultimo, NSW 2007, Australia

2 Red Sea Research Center, Division of Biological and Environmental Science and Engineering, King Abdullah University of Science and Technology (KAUST), Thuwal 23955-6900, Saudi Arabia

3 Department of Biology and Center for Environmental and Marine Studies, University of Aveiro, 3810-193 Aveiro, Portugal

4 Laboratoire d'Excellence «CORAIL», Institut de Recherche pour le Développement, Centre IRD de Nouméa, ENTROPIE (UMR250), BP A5, 98848 Nouméa Cedex, New Caledonia

5 Centre for Marine Science and Innovation, School of Biological, Earth and Environmental Sciences, The University of New South Wales, Sydney, NSW 2052, Australia

6 Department of Biology, University of Konstanz, Konstanz 78457, Germany 
observed that ITS2 profiles originating from Durusdinium taxa made up $<3 \%$ and a novel Symbiodinium ITS2 profile A1-A1v associated with A. pulchra. Bacterial community profiles were also highly divergent in corals from the lagoonal environment, whereas corals from the reef site were consistently dominated by Hahellaceae, Endozoicomonas. As such, differences in host-microorganism associations aligned with different physiologies and habitats. Our results argue that a multitude of host-microorganism associations are required to fulfill the changing nutritional demands of corals persisting into environments that parallel climate change scenarios.

Keywords Symbiodiniaceae - Mangrove $\cdot$ Microbial plasticity $\cdot$ Climate change $\cdot 16 \mathrm{~S}$ rRNA $\cdot$ ITS $2 \cdot$ Coral reef

\section{Introduction}

Global degradation of coral reefs under climate change has intensified efforts to understand whether and how corals may adapt to survive. Increasing intensity and frequency of marine heat waves resulting in mass coral bleaching (Hughes et al. 2018; Oliver et al. 2018), in conjunction with declines in coral calcification over multi-decadal timescales, paints a bleak future for coral reefs (De'ath et al. 2009). However, speciesspecific responses to thermal stress (Hughes et al. 2017) and low pH conditions (Okazaki et al. 2017), documented in reef environments (Hughes et al. 2017; Okazaki et al. 2017) and in vitro experimentations (Comeau et al. 2016), demonstrate capacity for coral resilience to stress. Furthermore, sites considered 'extreme' through persistent exposure of resident corals to conditions either comparable to (Fabricius et al. 2011) or even exceeding (Riegl and Purkis 2012) those predicted for reefs under climate change (IPCC 2014) are challenging our perceptions of the environmental parameters corals can tolerate (reviewed in Camp et al. 2018), and thus how reef landscapes may evolve under climate change.

Naturally extreme coral habitats have conditions close to the perceived thresholds for coral growth (Kleypas et al. 2009), but harbour coral species clearly adapted to the extreme prevailing conditions (Palumbi et al. 2014). Corals living in unusually warm waters, e.g. in the back-reef pools of American Samoa where at noon temperatures can reach $35{ }^{\circ} \mathrm{C}$ at low tide (Oliver and Palumbi 2011) or the Persian/ Arabian Gulf (PAG), the world's hottest sea (Riegl and Purkis 2012), have revealed a diversity of mechanisms that may contribute to thermal tolerance. These include specialised algal endosymbionts (Oliver and Palumbi 2011; Hume et al. 2015), changes to the microbiome (Ziegler et al. 2017) and host adaptation (Howells et al. 2016) from processes such as higher transcription of heat-responsive genes (Barshis et al. 2013). Vent sites where the release of
$\mathrm{CO}_{2}$ produces low $\mathrm{pH}$ gradients have revealed that physiological plasticity (Strahl et al. 2015), associated bacterial communities (Morrow et al. 2014), host traits (e.g. live tissue cover; Rodolfo-Metalpa et al. 2011) and gene expression changes (e.g. upregulation of ribosomal proteins) in Symbiodiniaceae (Kenkel et al. 2018) support holobiont survival. Whilst such evidence from singlestressor sites is invaluable for enhancing our understanding of coral environmental tolerance, it is unable to inform predictions of future reef form and function under climate change as elevated temperature, reduced $\mathrm{pH}$ and deoxygenation of seawater are predicted to impact reefs simultaneously (IPCC 2014). Consequently, we lack fundamental knowledge of how corals respond to multiple stressor scenarios predicted under climate change, operating over long generational timescales required for adaption (Hoegh-Guldberg et al. 2017; Torda et al. 2017).

We recently described a natural extreme mangrove lagoon in New Caledonia that harbours multiple coral species uniquely living in warm, acidic and low oxygen conditions (Camp et al. 2017). This lagoon provides a key location to study how this trio of stressors interact to impact corals as predicted under climate change, whilst also accounting for natural variance created by diel cycles (Camp et al. 2017). Whilst previous work has revealed that physiological plasticity supports coral survival in this lagoon (Camp et al. 2017), we lack knowledge of the coral-associated microorganisms (i.e. Symbiodiniaceae and bacteria) in this system and how they potentially support coral persistence. Coral-associated microorganisms can play important roles in holobiont adaption and survival in extreme environments (Bang et al. 2018; Camp et al. 2019) due to their ability to rapidly restructure to prevailing environmental conditions (Reshef et al. 2006; Hoegh-Guldberg et al. 2017; Ziegler et al. 2017) as well as their short generation times, allowing genetic changes to spread quickly throughout a population (Bang et al. 2018). For example, the type of Symbiodiniaceae can influence thermal tolerance (e.g. Suggett et al. 2017), whilst associated bacterial communities of some coral taxa can shift with environmental stress (Morrow et al. 2014; Vega Thurber et al. 2014; Ziegler et al. 2019), making microbiome flexibility a potential contributor to holobiont resilience (Ziegler et al. 2017; Pogoreutz et al. 2018; Ziegler et al. 2019).

Here, we sought to establish whether differences in holobiont physiology were accompanied by differences in microorganism structure (Symbiodiniaceae and bacteria) in lagoonal and adjacent reef habitats. Specifically, we hypothesised for the corals Acropora muricata, Acropora pulchra and Porites lutea that there would be common adjustments in holobiont physiology (photosynthesis to respiration; $\mathrm{P} / \mathrm{R}$ ) between habitats that is also accompanied by a difference in associated microorganisms. 


\section{Materials and methods}

\section{Study sites and species}

Corals were compared from a newly described 'extreme' shallow (1-2 m depth) lagoon, with corals from two adjacent shallow (1-3 m depth) reef sites at Bouraké, New Caledonia (described in Camp et al. 2017). In brief, the lagoon regularly exposes $>20$ coral species (24-35\% coral cover) to elevated temperatures $\left(>33.0^{\circ} \mathrm{C}\right)$, reduced total $\mathrm{pH} \quad\left(<7.3 \mathrm{pH}_{\mathrm{T}}\right)$ and low dissolved oxygen levels $\left(<2.3 \mathrm{mg} \mathrm{L}^{-1}\right)$ that represent some of the most extreme abiotic conditions documented for extant coral reefs (Camp et al. 2018; Fig. 1a-c). Environmental conditions within the lagoon $\left(21^{\circ} 56.915 \mathrm{~S} ; 165^{\circ} 59.577 \mathrm{E}\right)$ are regulated by both diel and tidal cycles (Fig. 1a-c). In contrast, two adjacent reef sites (R1 characteristic of an outer reef site, $21^{\circ} 59.784 \mathrm{~S} ; 165^{\circ} 54.992 \mathrm{E}$; R2 characteristic of an inner reef site, $21^{\circ} 58.189 \mathrm{~S} ; 165^{\circ} 58.184 \mathrm{E}$ ) exhibit relatively stable environmental conditions (Fig. 1), characteristic of present-day reef environments, and serve as control sites to the lagoon (Camp et al. 2017). We investigated three coral species that were dominant in the lagoon but also present at reef sites: R1, A. pulchra and P. lutea, R2, A. muricata, Supplementary Table 1).
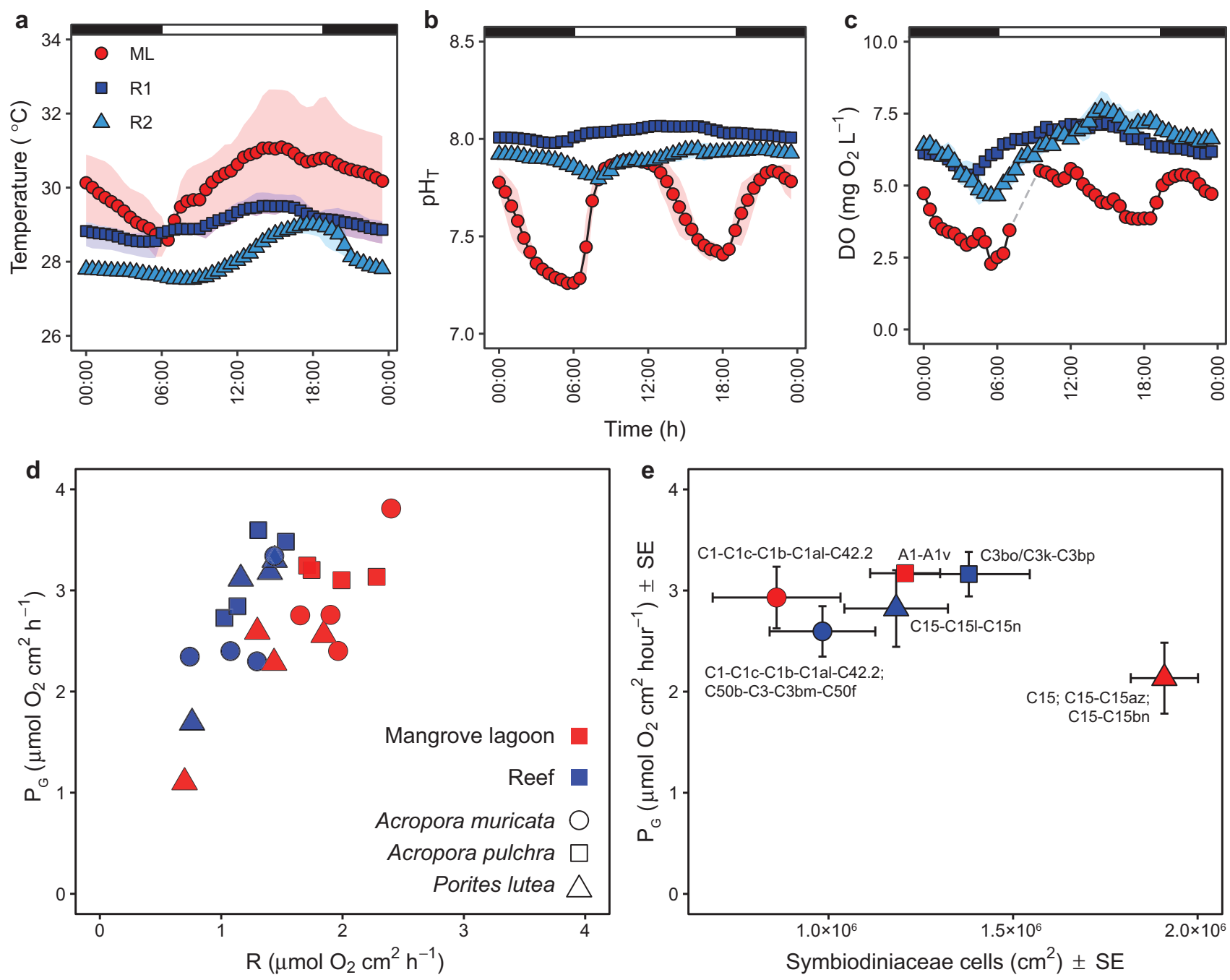

Fig. 1 a-c Diel physicochemical conditions for: a temperature, b total $\mathrm{pH}$ and $\mathbf{c}$ dissolved oxygen for the mangrove lagoon (ML) and two adjacent reef locations (R1 and R2) in Bouraké, New Caledonia. Measurements were conducted over a 3-d period (with the exception of dissolved oxygen in the ML which was 1 d) during February 2016 (additional data in Camp et al. 2017). Data shown are mean \pm minimum and maximum values (shaded areas). Dashed lines indicate

missing data. d Absolute rates of gross photosynthesis $\left(\mathrm{P}_{\mathrm{G}}\right)$ to respiration $(\mathrm{R})$ for the three coral species (Acropora muricata, Acropora pulchra, Porites lutea), across habitats (mangrove lagoon, reef), $n=4$ replicates, per species per habitat. e Mean \pm standard error rates of gross photosynthesis to number of Symbiodiniaceae cells per $\mathrm{cm}^{2}$ for each coral species and habitat. Lettering indicates the majority sequence for the ITS2-type profile of Symbiodiniaceae 


\section{Environmental and physiological data collection}

Data were collected on a spring tide over $3 \mathrm{~d}$ in February/ March 2016. Environmental data were obtained from the simultaneous deployment of SeaFET ${ }^{\mathrm{TM}}$ (Sea-Bird; temperature and $\mathrm{pH}$ ) and sonde (YSI; oxygen) sensors (30-min logging interval) within both habitats. Carbonate chemistry of the seawater (salinity, total alkalinity, $p \mathrm{CO}_{2}$, aragonite saturation state), light and total organic and inorganic carbon of marine sediment of the lagoon is described in Camp et al. (2017).

Measurements of net photosynthesis $\left(\mathrm{P}_{\mathrm{N}}\right)$ and respiration $(\mathrm{R})$ were conducted by $1 \mathrm{~h}$ in vitro coral incubations ( $n=4$ per species $<5 \mathrm{~cm}$ fragments, per habitat). Fragments were collected from their native environments and transported to the laboratory (within $1 \mathrm{~h}$ of collection) where they had a $4 \mathrm{~h}$ recovery period prior to incubation in a recirculating system containing seawater from their native environment. All non-live coral tissue was covered with parafilm prior to incubations to prevent biological alteration of incubated seawater. Incubations were conducted in $250 \mathrm{~mL}$ glass chambers filled with native seawater that was continuously mixed via a magnetic stir plate. Temperature was controlled via a water bath and kept within $0.5^{\circ} \mathrm{C}$ of the in situ ambient temperatures in the native environment (reef: $29.0^{\circ} \mathrm{C}$, lagoon: $30.9{ }^{\circ} \mathrm{C}$ ). Light conditions were $240 \mu \mathrm{mol} \mathrm{m} \mathrm{m}^{-2}$ (supplied via aquarium lights, Hopar) determined from the light saturation coefficient $\left(E_{k}\right)$ of the corals using a pulse amplitudemodulated fluorometer (Imaging PAM, Max/K.RGB, Walz $\mathrm{GmbH}$, Germany). Dark conditions were created by covering the chambers with blackout material.

Rates of $\mathrm{P}_{\mathrm{N}}$ and $\mathrm{R}\left(\mu \mathrm{mol} \mathrm{O}_{2} \mathrm{~cm}^{2} \mathrm{~h}^{-1}\right)$ were determined by changes in oxygen for each incubation chamber during the light and dark incubations, respectively, measured using a multi-meter and oxygen probe (FDO, WDW) (accuracy $\left.0.01 \mathrm{mg} \mathrm{L}^{-1}\right)$. Gross photosynthesis $\left(\mathrm{P}_{\mathrm{G}}\right)$ was calculated by the addition of $\mathrm{P}_{\mathrm{N}}$ and $\mathrm{R}$, with $\mathrm{P} / \mathrm{R}$ determined by $\mathrm{P}_{\mathrm{G}}$ divided by $\mathrm{R}$. Reported rates were corrected for any seawater biological activity and normalised to chamber volume, incubation time and coral surface area, which was determined by the advanced geometric technique (AGT; Naumann et al. 2009). Symbiodiniaceae cell counts were quantified using microscopy. Tissue (ca. $1 \mathrm{~cm}^{2}$ ) was removed from the coral skeleton with a waterpik and GF/Ffiltered $0.22 \mu \mathrm{m}$ seawater, with the resulting slurry homogenised. An aliquot was taken for cell quantification using a haemocytometer (Neubauer Haemocytometer, Fisher Scientific, Loughborough, UK). A total of eight replicate quadrats were counted for each sample as per Goyen et al. (2019). Differences per habitat for each species were determined by Welch's $t$ test (normality passed, Q-Q plots).

\section{Microbiome sampling and DNA extraction}

Coral fragments $(1 \mathrm{~cm})$ were removed from the same colonies used for the physiological sampling as well as one additional colony ( $n=5$, Supplementary Table 1$)$ and immediately preserved in RNAlater (Ambion, Life Technologies, Australia; as Vega Thurber et al. 2009) for genotyping of Symbiodiniaceae and bacteria based on amplicon sequencing of the ribosomal Internal Transcribed Spacer 2 (ITS2) region and 16S rRNA gene, respectively. Samples were stored at $-20{ }^{\circ} \mathrm{C}$ until processing. Prior to DNA extraction, excess RNAlater solution was removed using sterile Kim Wipes (Vega Thurber et al. 2009; Tout et al. 2015) before fragments were water-picked into sterile PBS-EDTA. DNA was extracted from the tissue slurry (i.e. coral mucus and tissue) using the Qiagen DNeasy Plant Mini Kit (Qiagen, Hilden, Germany) according to manufacturer's instructions, with an additional purification step using phenol/chloroform/isoamyl alcohol (25:24:1) prebuffered to $\mathrm{pH}$ 8. To disrupt the Symbiodiniaceae cells, $200 \mu \mathrm{L} 0.5 \mathrm{~mm}$ sterile glass beads (BioSpec, OK) were bead-beaten at $30 \mathrm{~Hz}$ for $90 \mathrm{~s}$ with a TissueLyser II (Qiagen, Germany). Quantity and quality of DNA were checked using a NanoDrop 2000C spectrophotometer (Thermo Fisher Scientific, MA). PCR amplifications were performed in triplicate reactions with a Qiagen Multiplex PCR Kit (Qiagen, Germany).

\section{PCR amplification, library preparation and sequencing}

For Symbiodiniaceae typing, amplification of the ITS2 region was done using the primers ITSintfor2 and ITS2reverse (Illumina sequencing adapters underlined) and following the PCR conditions of Arif et al. (2014):

ITSintfor2 5'-TCGTCGGCAGCGTCAGATGTGTATAAGAGACAGGAATTGCAGAACTCCGTG-3'

ITS2-reverse 5'-GTCTCGTGGGCTCGGAGATGTGTATAAGAGACAGGGGATCCA-

TATGCTTAAGTTCAGCGGGT-3'

For the bacterial 16S rRNA gene, the primers 16SMiSeqF-Andersson and 16SMiSeqR-Andersson were used (Andersson et al. 2008; Illumina sequencing adapters underlined) following the PCR conditions outlined in Ziegler et al. (2016):

16SMiSeqF-Andersson 5-TCGTCGGCAGCGTCAGATGTGTATAAGAGACAGAGGATTAGA-

TACCCTGGTA- $3^{\prime}$

16SMiSeqR-Andersson 5'-GTCTCGTGGGCTCGGAGATGTGTATAAGAGACAGCRRCACGAGCTGACGAC-3'.

For individual PCR reactions, DNA was aliquoted to between 12 and $50 \mathrm{ng}^{-\mathrm{L}}$, with $10 \mu \mathrm{L}$ Qiagen Mix, $0.5 \mu \mathrm{L}$ 
of each $10 \mathrm{M}$ primer mix, $1 \mu \mathrm{L}$ of DNA template and DNAse-free water to adjust the reaction volume to $20 \mu \mathrm{L}$. $5 \mu \mathrm{L}$ of each PCR product was run on an $1 \%$ agarose gel to visualise successful amplification. Sample triplicates were subsequently pooled and purified using the Agencourt AMPure XP magnetic bead system (Beckman Coulter, USA). Purified PCR products were subjected to an indexing PCR (eight cycles) to add Nextera XT indexing and sequencing adapters (Illumina) according to the manufacturer's protocol. Indexed amplicons were again purified, quantified on the QuBit (Quant-IT dsDNA Broad-Range Assay Kit; Invitrogen, USA) and pooled in equimolar ratios on the BioAnalyser (Agilent Technologies, USA). The final pooled library was purified on a $2 \%$ agarose gel to remove excess primer dimer. The library was sequenced at 8 pM with $10 \%$ phiX on the Illumina MiSeq, $2 \times 300 \mathrm{bp}$ paired-end version three chemistry according to the manufacturer's specifications at the Bioscience Core Lab (KAUST, Saudi Arabia).

\section{Phylogenetic and statistical analysis}

The SymPortal analytical framework (symportal.org, github.com/SymPortal; Hume et al. 2019) was used to predict putative Symbiodiniaceae genotypes (LaJeunesse et al. 2018) using the ITS2 marker. The framework uses next-generation amplicon sequencing data, to predict ITS2type profiles from specific sets of defining intragenomic ITS2 sequence variants (DIVs). In this study, these ITS2type profiles will be used as proxies for Symbiodiniaceae genotypes. Demultiplexed and paired forward and reverse.fastq.gz files outputted from the Illumina sequencing were submitted directly to SymPortal. Sequence quality control was conducted as part of the SymPortal pipeline using Mothur 1.39.5 (Schloss et al. 2009), the BLAST + suite of executables (Camacho et al. 2009) and minimum entropy decomposition (Eren et al. 2015).

Bacterial 16S rRNA gene amplicon sequences were processed in mothur version v1.36.1 according to the mothur MiSeq SOP (accession date 7 March 2018; Schloss et al. 2009). In brief, sequences were demultiplexed, assembled into contigs and quality-trimmed. Identical sequences (duplicates) were merged. Singletons and rare sequences $(n<10$ over all samples) were removed. Remaining sequences were aligned against the SILVA database release 128 (Pruesse et al. 2007) and pre-clustered (2 bp difference; Huse et al. 2010). Chimeric sequences were removed using the UCHIME command (Edgar et al. 2011). Sequences assigned to chloroplasts, mitochondria, archaea and eukaryotes were removed based on classification against the Greengenes database release gg_13_8_99 (McDonald et al. 2012). Kit contaminants (operational taxonomic units (OTUs) 0005, 0009, 0012, 0110, 0409, 0739: Brevibacter casei, B. aureum, Brachybacterium sp., Dietzia sp., Pseudomonas sp., Thermicanus sp.) were confirmed and removed based on sequencing of negative DNA extractions and negative PCRs (Salter et al. 2014). Sequences were subsequently clustered into OTUs (97\% similarity cut-off) and annotated against the Greengenes database (release gg_13_8_99, bootstrap $=60$; McDonald et al. 2012). Any OTU that made up more than $5 \%$ of the community in at least one sample that were not annotated to genus level was manually searched using BLAST to assign genus taxonomy with 97-99\% confidence. All raw sequence data are accessible under NCBI's BioProject (ITS2: PRJNA510616, 16S: PRJNA510614).

Differences in coral-associated Symbiodiniaceae and bacterial assemblages between coral species and habitats were analysed using permutational multivariate analysis of variance (PERMANOVA). Bacterial analysis was initially run at the OTU level and further analysed at the family level. Fixed factors (species and habitat) were nested according to hierarchy, and 999 permutations of residuals were conducted based on Bray-Curtis distances between square-root-transformed samples using the PRIMER-E software with the PERMANOVA+ add-on package v1.0.6 (Clarke and Gorley 2006). To calculate multivariate homogeneity of group dispersions for coral-associated bacterial communities, we ran the betadisper command in the R package vegan (Oksanen et al. 2018) on square-roottransformed data converted into a Bray-Curtis distance matrix. The betadisper was run for factors habitat, species and the interaction thereof. Differences in the homogeneity of group dispersions were tested with ANOVAs and followed by Tukey's honest significant differences (HSD) post hoc tests where applicable. In order to identify significantly associated bacterial OTUs, an indicator species analysis (ISA) was conducted using the command multipatt in the R package indicspec (Cáceres and Legendre 2009). The multipatt was run using the association function IndVal.g to simultaneously compute indicator values for significantly associated OTUs for habitat, species and the interaction thereof.

SIMPER analysis (Clarke 1993) was performed to investigate which OTUs contribute most to similarity between habitats and coral species, and between habitats within the same coral species. SIMPER analysis was also run to assess the similarity between coral species and habitat when only the low abundance taxa were considered. The low abundance category contains the sum of all bacterial taxa that did not contribute $>5 \%$ of the entire community in at least one sample. To assess differences in bacterial richness (Chao1) and alpha diversity indices (inverse Simpson's and Simpson's evenness) between habitats for each coral species, a series of Welch's t tests on $\log _{2^{-}}$ 
transformed data was undertaken in RStudio (RStudio Team 2015). For OTUs annotated as the genus Endozoicomonas that contributed $>5 \%$ of the community in at least one sample, Statistical Analysis of Metagenomic Profiles (STAMP) was undertaken to assess how taxonomic profiles varied per species between habitats using White's nonparametric t test (Parks et al. 2014). Five OTUs met the criteria for STAMP analysis: OTUs 0001, 0002, 0006, 0007, 0011. Finally, the core microbiome was determined across the whole dataset; core OTUs were defined as bacterial taxa present across all samples (as per Lawson et al. 2018).

\section{Results}

\section{Holobiont physiological response}

Abiotic conditions of the lagoon were more extreme and variable than the adjacent reef sites (Fig. 1), as previously reported in Camp et al. (2017). Despite the large difference in environmental conditions between habitats (Fig. 1), all three coral species had similar gross photosynthesis rates between habitats (Welch's t test, $\mathrm{p}>0.05$, $\mathrm{t}$ values in Supplementary Tables 2, 3; Fig. 1d). However, corals from the lagoon had increased respiration rates compared to corals from the reef (11-74\%, Fig. 1d). Consequently, P/R was reduced from $2.4 \pm 0.1$ in the reef site to $1.6 \pm 0.1$ within the lagoon.

\section{Stable site- and host-specific coral-Symbiodiniaceae associations}

Genotypic characterisation of the associated Symbiodiniaceae taxa revealed a host, species and habitat effect $\left(\right.$ PERMANOVA; pseudo $\mathrm{F}_{(2,23)}=11.866, p=0.001$; Supplementary Table 4). No ITS2-type profiles were shared between coral hosts. The two Acropora species exhibited different ITS2-type profiles and differential environment responses. A. muricata maintained the same ITS2-type profiles between the reef (site R2) and lagoon in all but one sample (ITS2-type profile C1-C1c-C1b-C1al-C42.2, Fig. 2). In contrast, $A$. pulchra is associated with different Symbiodiniaceae genotypes between habitats (lagoon and R1). At the lagoon, all A. pulchra samples are associated with a Symbiodinium taxon (ITS2-type profile A1-A1v; although lesser abundances of Cladocopium taxa were detected), whilst at the reef site (R1), all samples are associated with a Cladocopium taxon (ITS2-type profile C3bo/C3k-C3bp; Fig. 2). All P. lutea samples are associated with $\mathrm{C} 15$ radiation (Cladocopium) taxa. At the reef site (R1), all samples are associated with a single genotype (ITS2-type profile C15-C151-C15n), but at the lagoon, three distinct ITS2-type profiles (not including the reef ITS2-type profile) were identified in the four samples (C15, C15-C15az and C15-C15bn; Fig. 2). Notably, across all coral species, ITS2-type profile genotypes originating from Durusdinium taxa made up $<3 \%$ in each of only three samples.

Examination of Symbiodiniaceae cell density further revealed distinct patterns for the different coral hosts across habitats (Fig. 1e). Both Acropora spp. had the same Symbiodiniaceae cell densities between the two habitats (A. muricata reef: $9.84 \times 10^{5} \pm 1.44 \times 10^{5}$, lagoon: $1.21 \times 10^{6} \pm 9.45 \times 10^{5} ;$ A. pulchra reef: $1.38 \times$ $10^{6} \pm 1.65 \times 10^{5}$, lagoon: $1.21 \times 10^{6} \pm 9.45 \times 10^{5}$; Welch's t test, $p>0.05$, $\mathrm{t}$ values in Supplementary Table 5; Supplementary Fig. 1), and hence normalisation of gross photosynthesis rates to Symbiodiniaceae cell density remained unchanged between habitats (Fig. 1e, Welch's t test, $p>0.05$, t values in Supplementary Table 6; Supplementary Fig. 2). However, P. lutea displayed a higher density of Symbiodiniaceae cells in the lagoon $\left(1.91 \times 10^{6} \pm 9.11 \times 10^{4}\right.$ cell $\left.\mathrm{cm}^{2}\right)$ than the reef habitat $\left(1.18 \times 10^{6} \pm 1.42 \times 10^{5}\right.$ cell cm${ }^{2}$; Welch's t test, $\mathrm{t}_{(5)}=4.313, p=0.007$, Supplementary Table 5). Consequently, normalisation of gross photosynthesis to cell density resulted in reduced productivity per cell in the lagoon $\left(1.14 \times 10^{-6} \pm 2.31 \times 10^{-7} \mathrm{P}_{\mathrm{G}}\right.$ cell $\left.{ }^{-1}\right)$ relative to the reef habitat $\left(2.53 \times 10^{-6} \pm 5.08 \times 10^{-7} \mathrm{P}_{\mathrm{G}}\right.$ cell $^{-1}$, Welch's t test, $\mathrm{t}_{(6)}=2.517, \mathrm{p}=0.046$; Supplementary Tables 2, 6; Supplementary Fig. 2).

\section{Site-specific coral bacterial community plasticity}

The dataset comprised 22 16S rRNA gene amplicon libraries (2-5 replicates x3 species x2 sites; Supplementary Table 1) that had a total of 550,022 sequences $(937,411$ before removal of unwanted sequences), with an average length of $298 \mathrm{bp}$. Sequences were subsequently clustered into OTUs (97\% similarity cut-off) and after kit contaminants were removed, 489,893 sequences remained, with an average of 22,222.4 sequences per sample.

Coral host species and habitat were significant factors in determining the structure and composition of coral-associated bacterial communities (analysed at the OTU level, Fig. 3; PERMANOVA; pseudo $\mathrm{F}_{(2,21)}=4.359, \mathrm{p}=0.001$; Supplementary Table 7). Pairwise post hoc comparisons (PERMANOVA) revealed significant differences ( $\mathrm{t}$ values shown in Supplementary Table $7, p<0.05$ ) for all pairwise comparisons except that $A$. muricata and $P$. lutea had similar bacterial profiles within the reef habitat $\left(\mathrm{t}_{(4)}=1.405, p=0.179\right)$; low sample size $(n=2)$ for $P$. lutea could contribute to this finding. Multivariate homogeneity of group dispersion of bacterial communities was significantly different between lagoon corals and reef 


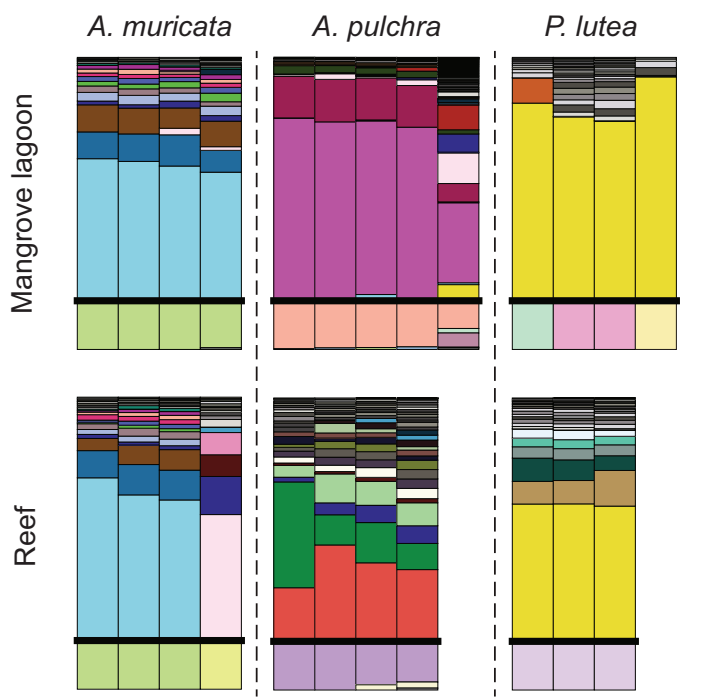

Fig. 2 Recovered ITS2 sequences and predicted ITS2 type profiles. The figure is organised as a 3-by-2 matrix of species (Acropora muricata, Acropora pulchra and Porites lutea) over habitat (mangrove lagoon and reef sites). For each cell of this matrix, results for the corresponding samples are plotted as stacked bar charts with a single column representing a sample. For each column in the stacked bar plots, the relative abundance of recovered ITS2 sequences is plotted above the horizontal black line, whilst the relative abundance of predicted ITS2-type profiles is plotted below. Only the 39 most abundant ITS2 sequences have been assigned colours. Additional

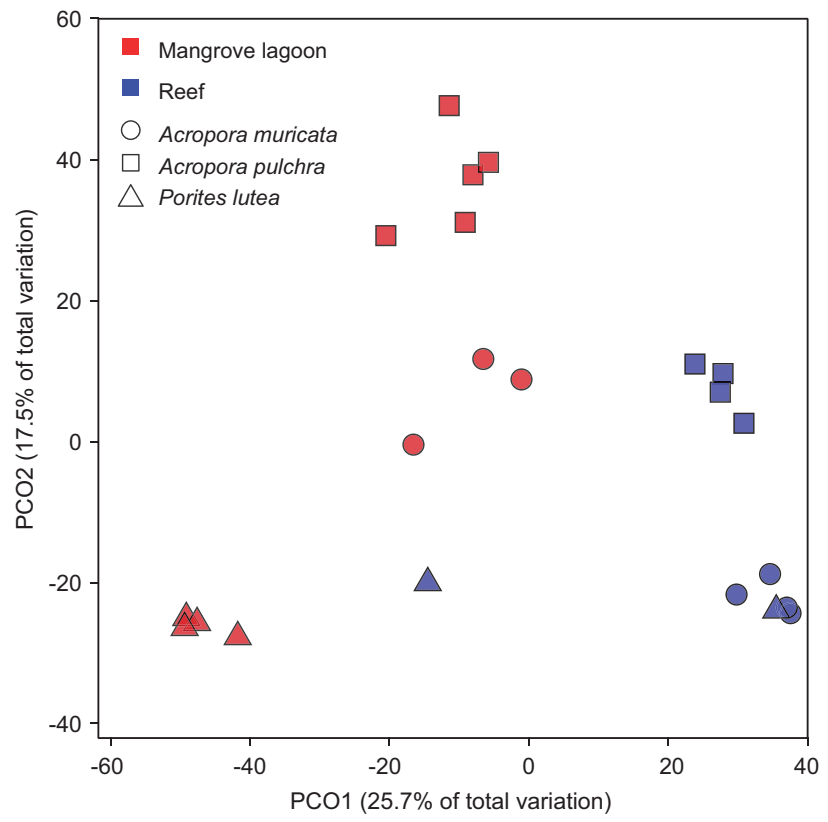

Fig. 3 Principal coordinate analysis (PCoA) of a Bray-Curtis similarity matrix of the coral-associated bacterial community composition at bacterial OTU level for each coral species replicate (Acropora muricata, Acropora pulchra, Porites lutea), across habitats. Data were square-root-transformed. Percentages on axes indicate variation explained by the two coordinates
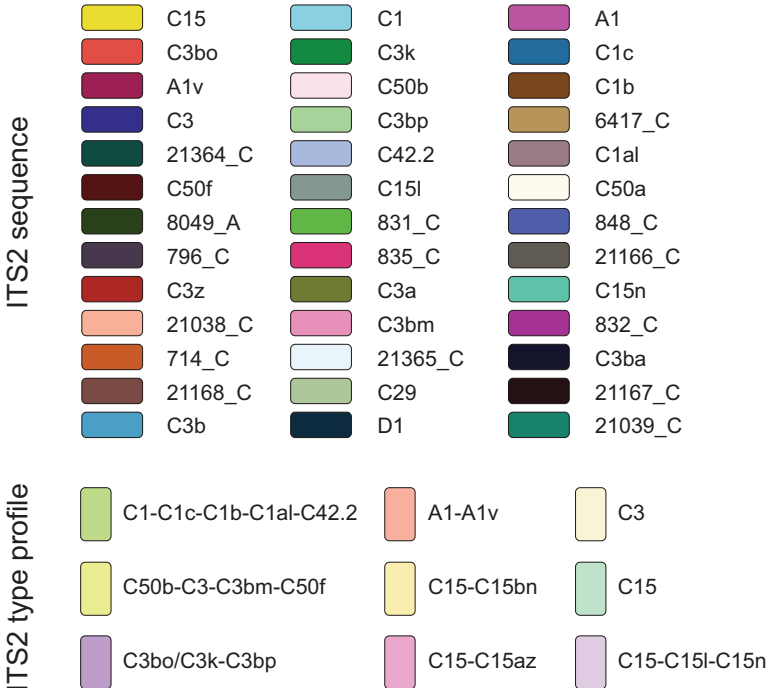

recovered sequences are coloured with a greyscale palette. Sequences that have been designated names, e.g. C3, C15 or C3bm, refer to sequences that are commonly found in the literature or have been used to characterise ITS2-type profiles as part of this or previous analyses that have been run through the SymPortal analytical framework. Less common sequences, and those that have not been used to characterise ITS2-type profiles, are named according to a unique database ID and their clade/genera, e.g. 6417_C refers to a sequence with ID 6417 derived from a taxon from the Cladocopium genera (clade $\mathrm{C}$ )

corals $($ ANOVA, $\mathrm{F}=72.673$, adjusted $p$ value $=0.014$, but not for coral species (ANOVA, $\mathrm{F}=0.333, \mathrm{p}$ value $=$ 0.721; Supplementary Table 8) or the interaction of both factors (ANOVA, $\mathrm{F}=26.674$, Tukey's adjusted $p$ values $>0.05$; Supplementary Table 8 ). Overall bacterial richness, diversity (Chao1 and inverse Simpson) and evenness were similar for all species, except A. muricata exhibited higher diversity (inverse Simpson $\mathrm{t}_{(4)}=7.090$, $p=0.002$ ) within the lagoon (Supplementary Tables 9, 10). P. lutea in the lagoon had much greater bacterial richness and diversity than in the reef, but this was not found to be significant (Supplementary Table 10).

Across all coral species and habitats, two OTUs were identified as core bacterial community members, OTU0001 (Gammaproteobacteria, Oceanospirillales, Hahellaceae, Endozoicomonas) and OTU0010 (Actinobacteria, Actinomycetales, Propionibacteriaceae, Propionibacterium acnes). Significantly associated bacterial OTUs (bacterial indicator taxa) identified by ISA varied by up to two orders of magnitude between habitats, coral species and the interaction thereof (Supplementary Table 11). For the mangrove lagoon, 64 bacterial indicator taxa were identified, whilst only 6 were identified across all corals for the reef environment. On the coral species level, 27 bacterial indicator taxa were identified for A. muricata, 6 for A. pulchra and 961 for $P$. lutea. Bacterial indicator taxa for 
the interaction of habitat and coral species were as follows: 18 for mangrove A. muricata, 8 for reef $A$. muricata, 5 each for mangrove and reef $A$. pulchra and a total of 655 for mangrove $P$. lutea. No bacterial indicators were identified for reef $P$. lutea, which is likely related to the low sample size.

Bacterial communities were most similar across habitats for A. muricata (37.18\%) and least for P. lutea (29.95\%). Each coral species had a different bacterial order contributing to the greatest similarly across habitats, Oceanospirillales for $A$. muricata (OTU0006), Chlamydiales for A. pulchra (OTU0003) and Enterobacteriales for P. lutea (OTU0023; Supplementary Table 12). Bacterial communities of all corals from the reef were dominated by OTUs 0001 and 0002 (both Gammaproteobacteria, Oceanospirillales, Hahellaceae, Endozoicomonas, Fig. 4; Supplementary Fig. 3), which contributed to $46.40 \%$ of similarity between the reef site corals (SIMPER analysis, Supplementary Table 14). In contrast, lagoon corals were less similar, with the top OTU (OTU0003; Chlamydiia, Chlamydiales, Simkaniaceae, Fritschea) only accounting for $13.84 \%$ similarity (SIMPER analysis, Supplementary Table 14). When only dominant low abundance taxa were considered, OTU0023 and OTU0025
(Gammaproteobacteria, Enterobacteriales, Enterobacteriaceae Shigella flexneri and Flavobacteriia, Flavobacteriales, Flavobacteriaceae, Actibacter sediminis, respectively; SIMPER analysis Supplementary Tables 15, 16) contributed $6.89 \%$ of the cumulative similarity between the lagoon site corals, whilst OTU0013 and OTU0069 (unclassified Gammaproteobacteria, Alteromonadales and unclassified Flavobacteriia, Flavobacteriales, Flavobacteriaceae, respectively; Supplementary Tables 15, 16), contributed $26.67 \%$ of the similarity between the reef site corals. In the lagoon, A. pulchra was dominated by OTU0003 and/ or OTU0004 (Gammaproteobacteria, Pseudomonadales, Moraxellaceae, Psychrobacter pacificensis), A. muricata was dominated by OTU0006 (Gammaproteobacteria, Oceanospirillales, Hahellaceae, Endozoicomonas) and OTU0010 (Actinobacteria, Actinomycetales, Propionibacteriaceae, Propionibacterium acnes) along with low abundance taxa, whilst $P$. lutea had a consistently associated compilation of families that included Desulfobacteriaceae, Desulfobulbaceae, Piscirickettsiaceae, unclassified Alteromonadales and unclassified families of Gammaproteobacteria (Fig. 4). The highest average relative abundance of a single low abundance OTU for $P$. lutea in the lagoon was $3.55 \pm 0.6 \%$ for

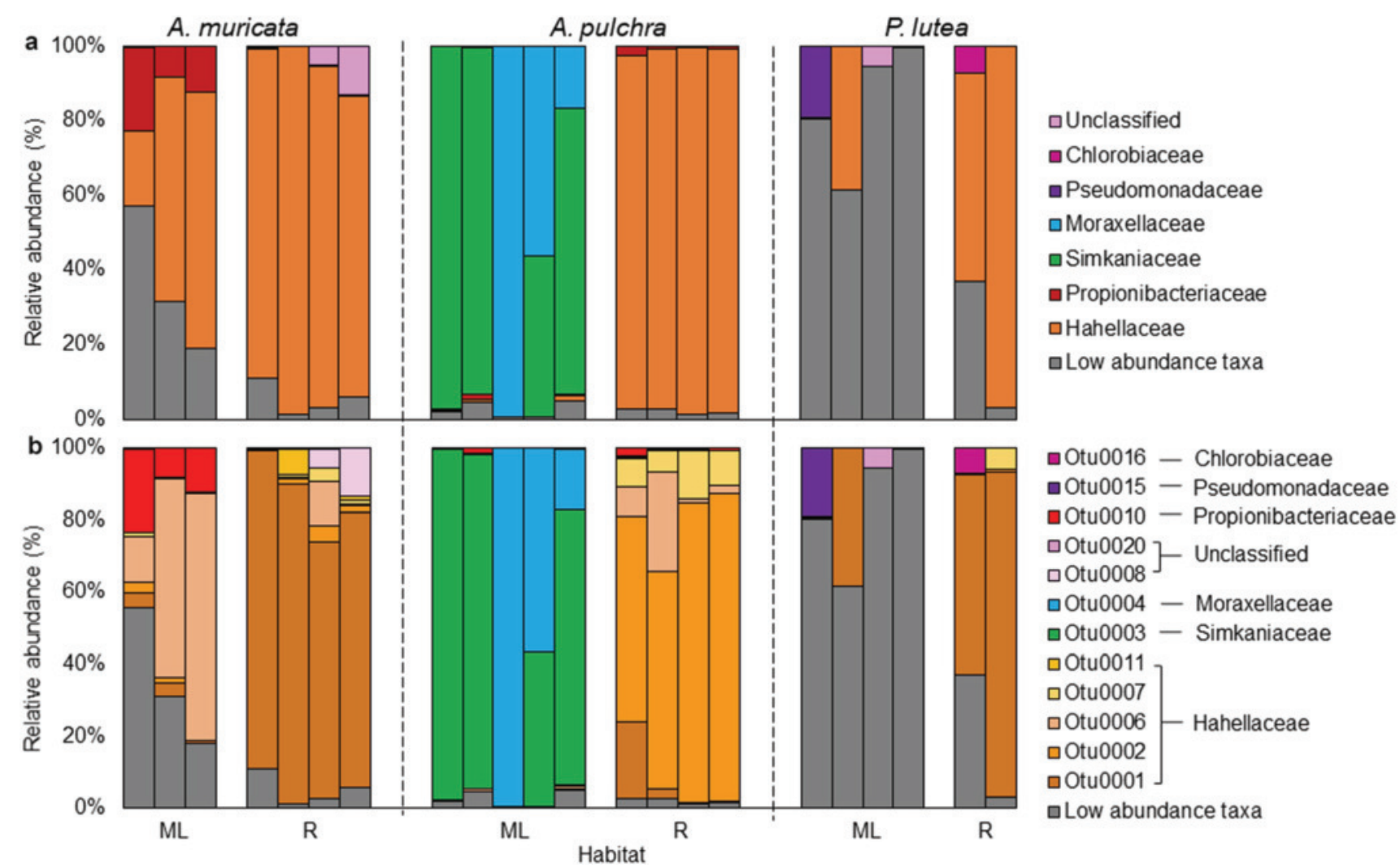

Fig. 4 Bacterial community composition (relative abundance \%) of each coral species replicate (Acropora muricata, Acropora pulchra, Porites lutea), across habitats (mangrove lagoon $=\mathrm{ML}$, reef $=\mathrm{R}$ ) at: a) OTU level and b) family level based on $16 \mathrm{~S}$ rRNA gene amplicon sequencing (Illumina MiSeq). Sequences were processed in mothur version v1.36.1n following the standard SOP (Schloss et al. 2009) and annotated in Greengenes (release gg_13_8_99; McDonald et al. 2012). The low abundance category contains the sum of all genera that did not contribute $>5 \%$ of the community in at least one sample 
OTU0014 (Gammaproteobacteria, Thiotrichales, Piscirickettsiaceae, unclassified; Supplementary Table 17).

Five OTUs (0001, 0002, 0006, 0007 and 0011) identified as belonging to the family Hahellaceae, genus Endozoicomonas, exhibited high-to-moderate relative abundances. An interesting observation was made with regard to coral species and habitat changes in the relative proportion of OTUs classified as Endozoicomonas (Supplementary Fig. 4). A. muricata was dominated by Endozoicomonas in both habitats; however, OTU0001 had the greatest proportion in the reef (STAMP, $p<0.001$ ), whereas OTU0006 had the greatest mean proportion in the lagoon (STAMP, $p=0.022$ ). P. lutea was also dominated by OTU0001 in the reef but exhibited large reductions in the abundance of any Endozoicomonas OTUs within the lagoon (less than 10\%). Across habitats, the mean proportional contribution of OTU0001 remained unchanged for $P$. lutea (STAMP, $p=0.804$ ), but notably, $P$. lutea in the lagoon was the only species to have OTU0006 and OTU0011 entirely absent. Finally, A. pulchra was dominated by Endozoicomonas in the reef (average relative abundance greater than 97\%), but experienced a large reduction in any Endozoicomonas OTUs in the lagoon (average relative abundance $0.5 \%$ ). OTU0002 had the greatest proportion in the reef (STAMP, $p<0.05$ ), whereas OTU0001 had the greatest mean proportion in the lagoon (STAMP, $p<0.05$ ). Thus, as for the responses observed for Symbiodiniaceae, no universal bacterial fingerprint was identified for the three host taxa persisting in the extreme lagoon.

\section{Discussion}

Bouraké lagoon corals have adapted to survive in arguably one of the most extreme extant coral habitats identified to date (Camp et al. 2018). Not only are the mean abiotic conditions extreme relative to the adjacent reefs (Fig. 1), but the repeatable and large variance in abiotic conditions creates periods of very hostile environmental conditions, e.g. temperatures above $32{ }^{\circ} \mathrm{C}, \mathrm{pH}$ below 7.4 and dissolved oxygen below $3 \mathrm{mg} \mathrm{L}^{-1}$, which the corals have to survive through. The trio of stressors acting in a repeatable and predictable way expose the resident corals to conditions exceeding Intergovernmental Panel on Climate Change (IPCC) climate predictions for 2100 (IPCC 2014). As previously reported in Camp et al. (2017), survival in this lagoon comes with trade-offs, such as reduced calcification rates (by 30-40\%) compared to adjacent reef habitats. However, the persistence of more than 20 coral species surviving and calcifying in this system challenges our understanding of conditions where corals can thrive (Camp et al. 2017). Heterotrophic potential appears fundamental to sustaining productivity, which adds to growing evidence from natural systems that heterotrophy can facilitate coral survival in unfavourable environmental conditions (Morgan et al. 2016; Camp et al. 2018; 2019). Low pH and elevated temperatures change the energetic requirements of fundamental biological processes such as calcification (Cohen and Holcomb 2009), whilst also impacting nutrient cycles and consequently resource availability (Hutchins and $\mathrm{Fu}$ 2017). As such, traits which enhance energy acquisition are likely beneficial for corals surviving into extremes (Camp et al. 2018).

\section{Stable site- and host-specific coral-Symbiodiniaceae associations}

We observed distinct symbiont community differences for each coral host species persisting into the lagoon, suggesting different strategies of environmental adaptation:

(i) A. muricata generally exhibited a conserved Symbiodiniaceae ITS2-type profile and cell density between habitats. Maintenance in productivity per cell without a difference in ITS2-type profile (C1-C1c-C1b-C1al-C42.2) suggests physiological resistance across environmental gradients and the capacity to adapt to extreme conditions (Camp et al. 2016). At a marginal reef in Hong Kong, 55 scleractinian coral species are predominantly associated with Cladocopium that share the C1 ITS2 sequence as their most abundant ITS2 sequence variant, indicating that the ability to acclimate or adapt to highly fluctuating (temperature, salinity, turbidity) environmental conditions may be a common trait within some taxa from the $\mathrm{C} 1$ radiation ( $\mathrm{Ng}$ and Ang 2016). Symbionts of the $\mathrm{C} 1$ radiation have also shown the capacity to locally adapt to different thermal regimes on the Great Barrier Reef (Howells et al. 2012). As Cladocopium of the $\mathrm{C} 1$ radiation are found across many environments and latitudes (LaJeunesse et al. 2003) with apparent high plasticity to adapt to a range of conditions, it appears likely that extensive cryptic species diversity exists that requires further characterisation, such as performed here by utilising defining intragenomic ITS2 sequence variants (DIVs), or with additional hypervariable markers. A. muricata was the only coral species in this present study to be sampled from the inner reef site (R2), which was in closer proximity to the lagoon than R1. Site R2 also has reduced water flow, which resulted in more pronounced diel effects than at R1 (Camp et al. 2017; Fig. 1). It is therefore possible that location has contributed to the conserved host-symbiont partnership of A. muricata observed between habitats here, and further sampling at the outer reef site (R1) will ultimately be required to verify the true extent of physiological flexibility for Cladocopium symbionts represented by the $\mathrm{C} 1-\mathrm{C} 1 \mathrm{c}-\mathrm{C} 1 \mathrm{~b}-\mathrm{C} 1 \mathrm{al}-\mathrm{C} 42.2$ ITS2-type profile. 
(ii) A. pulchra is associated with Cladocopium (ITS2type profile $\mathrm{C} 3 \mathrm{bo} / \mathrm{C} 3 \mathrm{k}-\mathrm{C} 3 \mathrm{bp}$; Fig. 2) on the reef and Symbiodinium (ITS2-type profile A1-A1v) in the lagoon. Despite the difference in associated genus, symbiont cell density and thus productivity per cell between habitats were unchanged. Differences in coral host/symbiont partnerships have been well documented across environments (LaJeunesse et al. 2014; Hume et al. 2015). As corals persist across different environments, the nutritional landscape can also change, making it potentially beneficial to associate with specific symbionts better capable of fulfilling host nutritional requirements. For example, recent work on Aiptasia has revealed how different symbiotic partners influence not only the fixation of available carbon to the host, but also carbohydrate availability, lipid storage and signalling molecules that could influence host physiology (Matthews et al. 2018). Local environmental conditions are therefore fundamentally important in determining the host's requirements and ultimately optimal symbiosis (Putnam et al. 2012).

Dominance of Symbiodinium ITS2-type profile A1-A1v associated with $A$. pulchra in the lagoon is intriguing because associations between Acropora and Symbiodinium are generally less common in the Indo-Pacific (LaJeunesse et al. 2009) and limited to a select few host species (LaJeunesse et al. 2004). However, Symbiodinium spp. with majority ITS2 sequence A3 have been found in higher abundance in acroporid juveniles on the Great Barrier Reef (Quigley et al. 2016) and in Japan (Suzuki et al. 2013). Our study suggests that these associations may be more widespread than previously recognised and should be further studied in habitats considered suboptimal. Given the exceptional genotypic and phenotypic diversity (likely) harboured within each of the common scleractinian-associating Symbiodiniaceae genera, mapping of phenotypic characters to the genus level should be undertaken with caution. However, Symbiodinium spp. have been suggested as potential opportunistic symbionts, more prone to a parasitic symbiotic state (Stat et al. 2008) due to: i) their basal lineage closely relating them to parasitic apicomplexans (Stat et al. 2008), ii) a strong free-living component of their life history and culturability (LaJeunesse 2002), iii) an ability to rapidly colonise aposymbiotic juveniles (Gómez-Cabrera et al. 2008) and iv) reports of increased abundance following thermal stress (Toller et al. 2001). Cultured Symbiodinium spp. have also been reported to release less carbon than Cladocopium spp., potentially limiting their nutritional benefit to the host (Stat et al. 2008). Such reduced carbon translocation potential is consistent with increased reliance on heterotrophy of the Acropora species within the lagoon. It is possible that the benefit of hosting Symbiodinium A1-A1v that can tolerate the extreme conditions of the lagoon comes at some cost, as seen for associations with a thermally tolerant Durusdinium symbiont which alters host growth rates (Cunning et al. 2015).

(iii) $P$. lutea maintained an association with Cladocopium of the $\mathrm{C} 15$ radiation across habitats, but there were distinct and more numerous C15 ITS2-type profiles (representative of different genotypes) in the lagoon. Symbiodiniaceae cell density also increased for corals in the lagoon, thereby reducing productivity per cell. Association between Indo-Pacific massive Porites spp. and Cladocopium that share the C15 ITS2 sequence is well documented over various temporal (Barshis et al. 2010) and spatial (LaJeunesse 2004; LaJeunesse et al. 2004) scales. Massive Porites spp. obtain symbionts from their maternal germline (vertical transmission; Baird et al. 2009), which is expected to enhance co-evolution of the holobiont to maximise nutritional cooperation (Ebert 2013).

Specificity of $P$. lutea with Cladocopium C15 appears central in facilitating host dispersal into diverse environmental regimes. Symbionts of the C15 lineage are considered ecologically successful (LaJeunesse 2004) and show greater photosynthetic stability under thermal stress than other C lineages, e.g. C8a (Fitt et al. 2009). C15 are also found in massive Porites living in thermally extreme habitats, such as the back-reef pools of American Samoa (Barshis et al. 2010). Interestingly, our findings suggest discrete C15 genotypes (distinct ITS2-type profiles) between habitats as recently reported for $P$. lutea in a mangrove lagoon on the Great Barrier Reef (Fig. 2; Camp et al. 2019). Further application of more resolute analyses to other datasets will be required to assess how divergent C15 symbiont lineages may be across environments, and to what extent prior methodological limitations in characterising the diversity of coral endosymbionts have limited our interpretation of diversity amongst Porites spp. symbiont associations (Hume et al. 2019). Again, distinct ITS2-type profiles retrieved for $P$. lutea between habitats suggest different genotypes that are potentially specifically adapted to the unique extreme abiotic conditions (Fig. 2).

Collectively, our results suggest that differences in coral host-Symbiodiniaceae associations to persist into extreme conditions are species-specific and that there is not a single strategy for survival. Interestingly, for lagoon corals, less than $3 \%$ of the ITS2-type profiles belong to the genus Durusdinium, putatively genotypes of the thermally tolerant species D. trenchii (Berkelmans and van Oppen 2006; LaJeunesse et al. 2014), and thus the focus on much stresstolerance research (Silverstein et al. 2017). The common assignment of thermally tolerant phenotype may come from a small number of common taxa, and less thermally resilient phenotypes may exist within this genotype. However, at sites where multiple abiotic parameters are considered extreme, e.g. in the PAG (Hume et al. 2016), 
the back-reef pools of American Samoa (Barshis et al. 2010), and the Bouraké lagoon of the present study, it appears that Symbiodiniaceae taxa other than Durusdinium are competitively dominant. Given that climate change will impact multiple abiotic parameters, it will be useful to renew focus on symbionts other than Durusdinium that could be better equipped to deal with multiple stressors acting in concert.

\section{Site-specific coral bacterial community plasticity}

As with the Symbiodiniaceae taxa, coral-associated bacterial community assemblages varied both amongst habitats and host species. There were, however, two core bacterial members found across all samples: an unclassified Endozoicomonas and Propionibacterium acnes. Endozoicomonas were proposed as potentially stable and prevalent symbiotic partners (Neave et al. 2017b), and $P$. acnes were previously found in Pocillopora damicornis (Yokouchi et al. 2006) and could contribute to biofilm formation in the corals mucus layer (Coenye et al. 2007; Li et al. 2017). Coral species-specific bacterial assemblages have been well documented for tropical corals (Rohwer et al. 2002; Neave et al. 2017a), with specific, uneven bacterial assemblages indicative of host selection in healthy corals (Bayer et al. 2013). Reef corals in this study had an uneven, specific microbiome dominated by one or two OTUs belonging to the family Hahellaceae, genus Endozoicomonas (Fig. 4). Based on the indicator species analysis (ISA), four of the six reef indicator bacteria were Endozoicomonas, supporting previous work that has found high abundance of Endozoicomonas in corals from healthy reefs (Bourne et al. 2016) and warranting functional work on this enigmatic bacterial genus (Pogoreutz et al. 2018).

The lagoon corals displayed significantly greater dispersion in their bacterial communities than the reef corals, an observation which has previously been linked to environmental stress in both corals and other organisms (Zaneveld et al. 2017). The lagoon corals also had nearly 10 times more bacterial indicator species than the reef corals with no common bacterial family dominant across lagoon coral species. A. muricata exhibited an increased abundance of Propionibacteriaceae (single OTU, Propionibacterium) and low abundance taxa. P. lutea was also characterised by an increase in low abundance taxa, but by a much larger $(>80 \%)$ magnitude to result in a more even microbiome that is uncharacteristic of healthy corals (Neave et al. 2017a). Of the low abundance taxa, the two largest contributing OTUs were assigned as unclassified Piscirickettsiaceae. In the back-reef pools of Ofu Island, members of the family Piscirickettsiaceae were significantly less abundant in moderate environments (moderately variable MV pool) than under more extreme environmental conditions (highly variable $\mathrm{HV}$ pool) (Ziegler et al. 2017), which suggests it could be a common coral bacteria found in more extreme, high variability lagoon environments. In contrast to A. muricata and $P$. lutea, A. pulchra was dominated by Simkaniaceae (single OTU, Fritschea) and/or Moraxellaceae (single OTU, Psychrobacter). Simkaniaceae have been commonly found in octocorals, but their function remains unknown (Neave et al. 2017a), whilst Moraxellaceae, Psychrobacter, have been reported in both healthy (Bourne 2005) and diseased corals (Luna et al. 2007). Intriguingly, species identification (with at least $97 \%$ similarity) of the Psychrobacter OTU was assigned to Psychrobacter pacificensis. Psychrobacter are often found in the coral mucus proportion of the coral holobiont (McKew et al. 2012) and have genes affiliated with carbon and nitrogen metabolism (e.g. rstA and rstB), as well as different nutrient conditions (e.g. nitrate respiration, narX, and phosphate limitation, phoR; Badhai et al. 2016). Due to their environmental versatility, occupying habitats as diverse as the deep sea (Maruyama et al. 2000), whale (Apprill et al. 2014) and shark skin (Pogoreutz et al. 2019) or coral mucus, Psychrobacter have therefore been postulated as highly adapted to continuously changing environmental conditions (Badhai et al. 2016), which may explain their prevalence in lagoon corals, where conditions fluctuate over diel and tidal cycles. Collectively, our data demonstrate that each coral species harbours highly divergent bacterial profiles at each habitat, which suggests species-specific plasticity in altering the bacterial composition in relation to the prevailing environmental conditions (Ziegler et al. 2019).

A dynamic relationship between bacterial communities and the environment has been suggested to select for members most beneficial to the holobiont (Reshef et al. 2006). Recent work (Hernandez-Agreda et al. 2018) proposes three components to the coral microbiome, the largest $(>96 \%)$ of which is a diverse 'environmentally responsive community' that is transient and reactive to ambient conditions. All three coral species in this study displayed plasticity in their bacterial communities between the contrasting environmental habitats, which could have physiological and ecological implications to the coral holobiont (sensu Reshef et al. 2006). Such plasticity in the bacterial composition could either hint towards microbiome flexibility (sensu Pogoreutz et al. 2018 and Ziegler et al. 2019) and, hence, signify differential ability of holobiont acclimation and/or adaptation through means of bacterial microbiome changes, or could alternatively reflect a 'halo' of a stressed microbiome around a constrained bacterial core community (Zaneveld et al. 2017). The distinct nature of the observed coral bacterial microbiome differences will need to be assessed further in future studies. 
Studying coral-associated bacterial communities in extreme systems is essential to our understanding of the long-term changes that occur under stress, when natural dynamics are at play (Meron et al. 2012; Ziegler et al. 2016; Camp et al. 2018). To date, the body of research on naturally extreme systems has been performed at sites with single stressors. For example, at the $\mathrm{CO}_{2}$ vent site in Ischia, Italy, low $\mathrm{pH}$ had a little impact on the Symbiodiniaceae or bacterial communities of two Mediterranean coral species (Meron et al. 2012). In contrast, at the vent site of Papua New Guinea, both A. millepora and P. cylindrica had very different bacterial communities (notably a $50 \%$ reduction in Endozoicomonas) than colonies from an adjacent 'typical pH' reef site less than $500 \mathrm{~m}$ away (Morrow et al. 2014). Similar to our findings, there were species-specific differences in how the coral bacterial assemblages changed at the Papua New Guinea vent site (Morrow et al. 2014), supporting the idea of varying microbiome community flexibility to environmental change. The ability for changes in bacterial community composition to aid host adaptation to extreme environments was supported by the observed reorganisation of the bacterial communities of $A$. hyacinthus reciprocally transplanted between thermally distinct pool in American Samoa (Ziegler et al. 2017). At the highly variable pool, there was a notable increase in the family Rhodospirillaceae, whilst Alteromonadaceae and Hahellaceae remained dominant families. Neither Rhodospirillaceae nor Alteromonadaceae were dominant families for corals at the Bouraké lagoon. Instead, similar to the findings from the Papua New Guinea vent site (Morrow et al. 2014), a consistent reduction in Hahellaceae, Endozoicomonas, was the only constant response between coral species.

Endozoicomonas are Gammaproteobacteria believed to play an important role for the coral holobiont, due to their prevalence in coral species across geographic locations (Bourne et al. 2008; Bourne et al. 2016; Pogoreutz et al. 2018). They exhibit differential degrees of host specificity (Neave et al. 2017b; Pogoreutz et al. 2018), with some Endozoicomonas likely to have co-diversified with their host (Bayer et al. 2013; Pollock et al. 2018). In this study, two OTUs identified as Endozoicomonas sp. dominated all of the reef corals, with high species specificity, e.g. all four A. muricata reef replicates were dominated by OTU0001 (Fig. 4). Our data suggest that under 'normal' reef conditions, coral species have associations with certain Endozoicomonas that are not present in corals in the extreme lagoon. Within the lagoon, only A. muricata had a significant association with Endozoicomonas (OTU0006), which is different than in corals from the reef (OTU0001). Endozoicomonas are metabolically diverse (Neave et al. 2016; Neave et al. 2017a), and metabolic sub-functionalisation or speciation of this bacterium within corals may occur
(Neave et al. 2017a; 2017b; Pogoreutz et al. 2018). In this context, it may also be possible that the different Endozoicomonas OTU facilitates alterations in metabolic requirements of $A$. muricata in the lagoon. In the other two coral species, Endozoicomonas was almost entirely absent (apart from $n=1 P$. lutea) as a dominant bacterial member for corals native to the lagoon. Our findings suggest that differences in Endozoicomonas, at least for the species studied, may be an indicator of habitat suitability (Roder et al. 2015).

Whilst no natural extreme system can truly encapsulate future predicted climate scenarios, these systems provide an invaluable tool to increase our understanding of coral holobiont adaptability and plasticity under extreme environmental conditions, which may become the norm for coral reefs into the future. Our work demonstrates that a common physiological response can coincide with divergent underlying microbial communities in three coral hosts in the Bouraké lagoon. Whilst currently we cannot ascertain function, we hypothesise that changes in the resource landscape and requirements of corals persisting into the extreme lagoon may ultimately result in differential plasticity and specificity of microbial associations to meet their metabolic requirements. Further work will be required to substantiate this hypothesis and also explore the role of the host in shaping microbial associations. Also, to understand the role that the host can play in supporting survival into extreme environments. Our findings challenge our understanding of the abiotic conditions some corals can survive under and reveal how microorganism flexibility is an important part of holobiont adaption to survival in environmental extremes.

Acknowledgements We wish to express our deepest thanks to C. Payri and the captains of the IRD vessels for their fieldwork assistance. We also thank B. Pelletier and the Grand Observatoire du Pacifique du Sud (GOPS), for use of their instruments and facilities, and F. Benzoni for verifying our coral taxonomic identification.

Authors' contributions EFC, DJS, FH and RRM led the project planning. EFC and DJS designed the study. EFC, DJS, MRN, MZ, RRM and SGG contributed to data collection. EFC undertook the DNA extractions with $\mathrm{CRV}$ carrying out the sequencing. $\mathrm{CP}, \mathrm{BCCH}$, EFC, MRN and CRV conducted the data analysis. MRN, EFC and $\mathrm{BCCH}$ compiled the figures. EFC, DJS and CRV led the writing of the manuscript with all authors contributing to the final manuscript preparation.

Funding EFC was supported by an Endeavour Postdoctoral Fellowship to collect and process the data. The contribution of DJS and EFC to manuscript writing and final preparation was through an Australian Research Council Discovery Project (160100271 to D.JS). $\mathrm{BCCH}, \mathrm{CP}$ and $\mathrm{CRV}$ acknowledge funding by the King Abdullah University of Science and Technology (KAUST) and would like to thank the Bioscience Core Lab (BCL) at KAUST for sequencing assistance. We also wish to thank to Fonds Pacifique for financial support (Project 1722 'Identifying the value of New Caledonia's 
"extreme" corals to manage reefs under climate change' to DJS, RRM, EFC) in funding the workshop COLIMATIC where data for this manuscript were first discussed.

\section{Compliance with ethical standards}

Conflict of interest The authors declare that they have no conflict of interest.

Ethics approval and consent to participate Not applicable

Consent for publication Not applicable.

\section{References}

Andersson AF, Lindberg M, Jakobsson H, Bäckhed F, Nyrén P, Engstrand L (2008) Comparative analysis of human gut microbiota by barcoded pyrosequencing. PloS one 3(7):e2836

Apprill A, Robbins J, Eren AM, Pack AA, Reveillaud J, Mattila D, Moore M, Niemeyer M, Moore KM, Mincer TJ (2014) Humpback whale populations share a core skin bacterial community: towards a health index for marine mammals? PLoS One 9(3):e90785

Arif C, Daniels C, Bayer T, Banguera-Hinestroza E, Barbrook A, Howe CJ, LaJeunesse TC, Voolstra CR (2014) Assessing Symbiodinium diversity in scleractinian corals via next-generation sequencing-based genotyping of the ITS2 rDNA region. Mol Ecol 23(17):4418-4433

Badhai J, Ghosh TS, Das SK (2016) Composition and functional characterization of microbiome associated with mucus of the coral Fungia echinata collected from Andaman Sea. Front Microbio 7:936

Baird AH, Guest JR, Willis BL (2009) Systematic and biogeographical patterns in the reproductive biology of scleractinian corals. Ann Rev Ecol Evol Syst Syst. 40:551-571

Bang C, Dagan T, Deines P, Dubilier N, Duschl WJ, Fraune S, Hentschel U, Hirt H, Hülter N, Lachnit T, Picazo D, Pita L, Pogoreutz C, Rädecker N, Saad MM, Schmitz RA, Schulenburg H, Voolstra CR, Weiland-Bräuer N, Ziegler M, Bosch TCG (2018) Metaorganisms in extreme environments: do microbes play a role in organismal adaptation? Zoology 127:1-19

Barshis DJ, Stillman JH, Gates RD, Toonen RJ, Smith LW, Birkeland C (2010) Protein expression and genetic structure of the coral Porites lobata in an environmentally extreme Samoan back reef: does host genotype limit phenotypic plasticity? Mol Ecol 19:1705-1720

Barshis DJ, Ladner JT, Oliver TA, Seneca FO, Traylor-Knowles N, Palumbi SR (2013) Genomic basis for coral resilience to climate change. Proc Natl Acad Sci USA 110:1387-1392

Bayer T, Neave MJ, Alsheikh-Hussain A, Aranda M, Yum LK, Mincer T, Hughen K, Apprill A, Voolstra CR (2013) The microbiome of the Red Sea coral Stylophora pistillata is dominated by tissue-associated Endozoicomonas bacteria. App Environ Microbio 79:4759-4762
Berkelmans R, van Oppen MJH (2006) The role of zooxanthellae in the thermal tolerance of corals: a 'nugget of hope' for coral reefs in an era of climate change. Proc R Soc B 273:2305-2312

Bourne DG (2005) Microbiological assessment of a disease outbreak on corals from Magnetic Island (Great Barrier Reef, Australia). Coral Reefs 24:304-312

Bourne D, Iida Y, Uthicke S, Smith-Keune C (2008) Changes in coral-associated microbial communities during a bleaching event. ISME J 2:350-363

Bourne DG, Morrow KM, Webster NS (2016) Insights into the coral microbiome: underpinning the health and resilience of reef ecosystems. Ann Rev Microbio 8:317-340

Camacho C, Coulouris G, Avagyan V, Ma N, Papadopoulos J, Bealer K, Madden TL (2009) BLAST+: architecture and applications. BMC bioinformatics 10(1):421

Camp EF, Smith DJ, Evenhuis C, Enochs I, Manzello D, Woodcock S, Suggett DJ (2016) Acclimatization to high-variance habitats does not enhance physiological tolerance of two key Caribbean corals to future temperature and pH. Proc R Soc B 283:20160442

Camp EF, Nitschke MR, Rodolfo-Metalpa R, Houlbreque F, Gardner SG, Smith DJ, Zampighi M, Suggett DJ (2017) Reef-building corals thrive within hot-acidified and deoxygenated waters. Sci Reps 7:2434

Camp EF, Schoepf V, Mumby PJ, Hardtke LA, Rodolfo-Metalpa R, Smith DJ, Suggett DJ (2018) The future of coral reefs subject to rapid climate change: lessons from natural extreme environments. Front Mar Sci 5:4

Camp EF, Edmondson J, Doheny A, Rumney J, Grima AJ, Huete A, Suggett DJ (2019) Mangrove lagoons of the Great Barrier Reef support coral populations persisting under extreme environmental conditions. Mar Ecol Prog Ser 625:1-14

Clarke KR (1993) Non-parametric multivariate analyses of changes in community structure. Australian Journal of Ecol 18(1):117-143

Clarke KR, Gorley RN (2006) PRIMER v6. 2006. user manual/tutorial. PRIMER-E, Plymouth

Coenye T, Peeters E, Nelis HJ (2007) Biofilm formation by Propionibacterium acnes is associated with increased resistance to antimicrobial agents and increased production of putative virulence factors. Res Microbiol 158:386-392

Cohen AL, Holcomb M (2009) The future of ocean biogeochemistry in a high-CO2 world. Oceanogr 22:118-127

Comeau S, Carpenter RC, Edmunds PJ (2016) Effects of $\mathrm{pCO}_{2}$ on photosynthesis and respiration of tropical scleractinian corals and calcified algae. ICES J Mar Sci 74(109):2-102

Cunning R, Gillette P, Capo T, Galvez K, Baker AC (2015) Growth tradeoffs associated with thermotolerant symbionts in the coral Pocillopora damicornis are lost in warmer oceans. Coral Reefs 34:155-160

Cáceres MD, Legendre P (2009) Associations between species and groups of sites: indices and statistical inference. Ecol 90(12):3566-3574

De'ath G, Lough JM, Fabricius KE (2009) Declining coral calcification on the Great Barrier Reef. Sci 323:116-119

Ebert D (2013) The epidemiology and evolution of symbionts with mixed-mode transmission. Ann Review Ecol Evol Systematics $44: 7.1-7.21$

Edgar RC, Haas BJ, Clemente JC, Quince C, Knight R (2011) UCHIME improves sensitivity and speed of chimera detection. Bioinfor 27(16):2194-2200

Eren AM, Morrison HG, Lescault PJ, Reveillaud J, Vineis JH, Sogin ML (2015) Minimum entropy decomposition: unsupervised oligotyping for sensitive partitioning of high-throughput marker gene sequences. ISME 9:968

Fabricius KE, Langdon C, Uthicke S, Humphrey C, Noonan S, De' ath G (2011) Losers and winners in coral reefs acclimatized to elevated carbon dioxide concentrations. Nat Clim Change 1:165 
Fitt WK, Gates RD, Hoegh-Guldberg O, Bythell JC, Jatkar A, Grottoli AG, Gomez M, Fisher P, Lajuenesse TC, Pantos O, Iglesias-Prieto R, Franklin DJ, Rodrigues LJ, Torregiani JM, van Woesik R, Lesser MP (2009) Response of two species of IndoPacific corals, Porites cylindrica and Stylophora pistillata, to short-term thermal stress: the host does matter in determining the tolerance of corals to bleaching. J Exp Mar Biol Ecol 373:102-110

Goyen S, Camp EF, Fujise L, Lloyd A, Nitschke MR, LaJeunensse T, Kahlke T, Ralph PJ, Suggett D (2019) Mass coral bleaching of $P$. versipora in Sydney Harbour driven by the 2015-2016 heatwave. Coral Reefs 38(4):815-830

Gómez-Cabrera MD, Ortiz JC, Loh WK, Ward S, Hoegh-Guldberg O (2008) Acquisition of symbiotic dinoflagellates (Symbiodinium) by juveniles of the coral Acropora longicyathus. Coral Reefs 27:219-226

Hernandez-Agreda A, Leggat W, Bongaerts P, Herrera C, Ainsworth TD (2018) Rethinking the coral microbiome: simplicity exists within a diverse microbial biosphere. MBio 9:e00812-e00818

Hoegh-Guldberg O, Poloczanska ES, Skirving W, Dove S (2017) Coral reef ecosystems under climate change and ocean acidification. Front Mar Sci 29:4-158

Howells EJ, Beltran VH, Larsen NW, Bay LK, Willis BL, van Oppen MJH (2012) Coral thermal tolerance shaped by local adaptation of photosymbionts. Nat Clim Chang 2:116-120

Howells EJ, Abrego D, Meyer E, Kirk NL, Burt JA (2016) Host adaptation and unexpected symbiont partners enable reef-building corals to tolerate extreme temperatures. Global Change Biol 22:2702-2714

Hume BCC, D'Angelo C, Smith EG, Stevens JR, Wiedenmann J (2015) Symbiodinium thermophilum sp. nov., a thermotolerant symbiotic alga prevalent in corals of the world's hottest sea, the Persian/Arabian Gulf. Sci Rep 5:8562

Hume BC, Voolstra CR, Arif C, D'Angelo C, Burt JA, Eyal G, Loya Y, Wiedenmann J (2016) Ancestral genetic diversity associated with the rapid spread of stress-tolerant coral symbionts in response to Holocene climate change. Proc Nat Acad Sci 113(16):4416-4421

Hume BCC, Smith EG, Ziegler M, Warrington HJM, Burt JA, LaJeunesse TC, Wiedenmann J, Voolstra CR (2019) SymPortal: a novel analytical framework and platform for coral algal symbiont next-generation sequencing ITS2 profiling. Molecular Ecology Resources 19:1063-1080

Hughes TP, Barnes ML, Bellwood DR, Cinner JE, Cumming GS, Jackson JB, Kleypas J, van de Leemput IA, Lough JM, Morrison TH, Palumbi SR, van Nes EH, Scheffer M (2017) Coral reefs in the Anthropocene. Nat 546(7656):82

Hughes TP, Anderson KD, Connolly SR, Heron SF, Kerry JT, Lough JM, Baird AH, Baum JK, Berumen ML, Bridge TC, Claar DC, Eakin CM, Gilmour JP, Graham NAJ, Harrison H, Hobbs J-PA, Hoey AS, Hoogenboom M, Lowe RJ, McCulloch MT, Pandolfi JM, Pratchett M, Schoepf V, Torda G, Wilson SK (2018) Spatial and temporal patterns of mass bleaching of corals in the Anthropocene. Sci 359:80-83

Huse SM, Welch DM, Morrison HG, Sogin ML (2010) Ironing out the wrinkles in the rare biosphere through improved OTU clustering. Env Microbiol 12:1889-1898

Hutchins DA, Fu F (2017) Microorganisms and ocean global change. Nature Microbio 2:17058

IPCC (2014) Climate Change 2014: synthesis report. Contribution of working groups I, II and III to the 5th assessment report of the intergovernmental panel on climate change [Core Writing Team, R. K. Pachauri and L. A. Meyer (eds.)]. IPCC, Geneva, Switzerland, $151 \mathrm{pp}$

Kenkel CD, Moya A, Strahl J, Humphrey C, Bay LK (2018) Functional genomic analysis of corals from natural $\mathrm{CO} 2$-seeps reveals core molecular responses involved in acclimatization to ocean acidification. Global Change Biol 24:158-171

Kleypas JA, McManus JW, Meñez LA (2009) Environmental limits to coral reef development: where do we draw the line? Am Zool $39: 146-159$

LaJeunesse TC (2002) Diversity and community structure of symbiotic dinoflagellates from Caribbean coral reefs. Mar Bio $141: 387-400$

LaJeunesse TC (2004) "Species" radiations of symbiotic dinoflagellates in the Atlantic and Indo-Pacific since the Miocene-Pliocene transition. Mol Biol Evol 22:570-581

LaJeunesse TC, Loh WK, Van Woesik R, Hoegh-Guldberg O, Schmidt GW, Fitt WK (2003) Low symbiont diversity in southern Great Barrier Reef corals, relative to those of the Caribbean. Limnol Oceanography 48:2046-2054

LaJeunesse TC, Bhagooli R, Hidaka M, Done T, Schmidt GW, Fitt WK, Hoegh-Guldberg O (2004) Closely related Symbiodinium spp. differ in relative dominance in coral reef host communities across environmental, latitudinal and biogeographic gradients. Mar Ecol Prog Seri 284:147-161

LaJeunesse TC, Loh W, Trench RK (2009) Do introduced endosymbiotic dinoflagellates 'take'to new hosts? Biological Invasions 11:995-1003

LaJeunesse TC, Wham DC, Pettay DT, Parkinson JE, Keshavmurthy S, Chen CA (2014) Ecologically differentiated stress-tolerant endosymbionts in the dinoflagellate genus Symbiodinium (Dinophyceae) Clade D are different species. Phycologia 53(4):305-319

LaJeunesse TC, Parkinson JE, Gabrielson PW, Jeong HJ, Reimer JD, Voolstra CR, Santos SR (2018) Systematic revision of Symbiodiniaceae highlights the antiquity and diversity of coral endosymbionts. Current Biol 28:2570-2580

Lawson CA, Raina JB, Kahlke T, Seymour JR, Suggett DJ (2018) Defining the core microbiome of the symbiotic dinoflagellate, Symbiodinium. Environmental Microbio Rep 10(1):7-11

Li J, Kuang W, Long L, Zhang S (2017) Production of quorumsensing signals by bacteria in the coral mucus layer. Coral Reefs 36(4):1235-1241

Luna GM, Biavasco F, Danovaro R (2007) Bacteria associated with the rapid tissue necrosis of stony corals. Environmental Microbiology 9:1851-1857

Maruyama A, Honda D, Yamamoto H, Kitamura K, Higashihara T (2000) Phylogenetic analysis of psychrophilic bacteria isolated from the Japan Trench, including a description of the deep-sea species Psychrobacter pacificensis sp. nov. Int J System Evo Microbio 50:835-846

Matthews JL, Oakley CA, Lutz A, Hillyer KE, Roessner U, Grossman AR, Weis VM, Davy SK (2018) Partner switching and metabolic flux in a model cnidarian-dinoflagellate symbiosis. Proc Biol Sci 285:1892

McDonald D, Price MN, Goodrich J, Nawrocki EP, DeSantis TZ, Probst A, Andersen GL, Knight R, Hugenholtz P (2012) An improved Greengenes taxonomy with explicit ranks for ecological and evolutionary analyses of bacteria and archaea. ISME 6(3):610

McKew BA, Dumbrell AJ, Daud SD, Hepburn L, Thorpe E, Mogensen L, Whitby C (2012) Characterization of geographically distinct bacterial communities associated with coral mucus produced by Acropora spp. and Porites spp. Appl Environ Microbiol 78:5229-5237

Meron D, Rodolfo-Metalpa R, Cunning R, Baker AC, Fine M, Banin $\mathrm{E}$ (2012) Changes in coral microbial communities in response to a natural $\mathrm{pH}$ gradient. ISME J 6:1775

Morgan KM, Perry CT, Smithers SG, Johnson JA, Daniell JJ (2016) Evidence of extensive reef development and high coral cover in 
nearshore environments: implications for understanding coral adaptation in turbid settings. Sci Rep 19:29616

Morrow KM, Bourne DG, Humphrey C, Botté ES, Laffy P, Zaneveld J, Uthicke S, Fabricius KE, Webster NS (2014) $\mathrm{CO}_{2}$ seeps reveal future trajectories for host-microbial associations in corals and sponges. ISME 9:894

Naumann MS, Niggl W, Laforsch C, Glaser C, Wild C (2009) Coral surface area quantification-evaluation of established techniques by comparison with computer tomography. Coral Reefs 28:109-117

Neave MJ, Apprill A, Ferrier-Pagès C, Voolstra CR (2016) Diversity and function of prevalent symbiotic marine bacteria in the genus Endozoicomonas. App Microbiol Biotechnol 100:8315-8324

Neave MJ, Michell CT, Apprill A, Voolstra CR (2017a) Endozoicomonas genomes reveal functional adaptation and plasticity in bacterial strains symbiotically associated with diverse marine hosts. Sci Rep 7:40579

Neave MJ, Rachmawati R, Xun L, Michell CT, Bourne DG, Apprill A, Voolstra CR (2017b) Differential specificity between closely related corals and abundant Endozoicomonas endosymbionts across global scales. ISME J 11:186

Ng TY, Ang P (2016) Low symbiont diversity as a potential adaptive strategy in a marginal non-reefal environment: a case study of corals in Hong Kong. Coral Reefs 35:941-957

Okazaki RR, Towle EK, van Hooidonk R, Mor C, Winter RN, Piggot AM, Cunning R, Baker AC, Klaus JS, Swart PK, Langdon C (2017) Species-specific responses to climate change and community composition determine future calcification rates of Florida Keys reefs. Global Change Biol 23:1023-1035

Oksanen J, Blanchet FG, Friendly M, Kindt R, Legendre P, McGlinn D, Minchin PR, O'Hara RB, Simpson GL, Solymos P, Stevens MH (2018) vegan: community ecology package. R package version $2.5-2$

Oliver TA, Palumbi SR (2011) Many corals host thermally resistant symbionts in high-temperature habitat. Coral Reefs 30:241-250

Oliver EC, Donat MG, Burrows MT, Moore PJ, Smale DA, Alexander LV, Benthuysen JA, Feng M, Gupta AS, Hobday AJ, Holbrook NJ, Perkins-Kirkpatrick SE, Scannell HA, Straub SC, Wernberg T (2018) Longer and more frequent marine heatwaves over the past century. Nat Commun 9(1):1324

Palumbi SR, Barshis DJ, Traylor-Knowles N, Bay RA (2014) Mechanisms of reef coral resistance to future climate change. Sci 344:895-898

Parks DH, Tyson GW, Hugenholtz P, Beiko RG (2014) STAMP: statistical analysis of taxonomic and functional profiles. Bioinformatics 30:3123-3124

Pogoreutz C, Rädecker N, Cárdenas A, Gärdes A, Wild C, Voolstra CR (2018) Dominance of Endozoicomonas bacteria throughout coral bleaching and mortality suggests structural inflexibility of the Pocillopora verrucosa microbiome. Ecol Evol 8:2240-2252

Pogoreutz C, Gore MA, Perna G, Millar C, Nestler R, Ormond RF, Clarke CR, Voolstra CR (2019) Similar bacterial communities on healthy and injured skin of black tip reef sharks. BMC Anim Microbiome 1(1):9

Pollock FJ, McMinds R, Smith S, Bourne DG, Willis BL, Medina M, Thurber RV, Zaneveld JR (2018) Coral-associated bacteria demonstrate phylosymbiosis and cophylogeny. Nat Com 9:4921

Pruesse E, Quast C, Knittel K, Fuchs BM, Ludwig W, Peplies J, Glöckner FO (2007) SILVA: a comprehensive online resource for quality checked and aligned ribosomal RNA sequence data compatible with ARB. Nucleic Acids Res 35(21):7188-7196

Putnam HM, Stat M, Pochon X, Gates RD (2012) Endosymbiotic flexibility associates with environmental sensitivity in scleractinian corals. Proc Royal Soc B Bio Sci 29:20121454

Quigley KM, Willis BL, Bay LK (2016) Maternal effects and Symbiodinium community composition drive differential patterns in juvenile survival in the coral Acropora tenuis. Royal Society Open Sci 3(10): 160471

R Studio Team (2015) RStudio: integrated development for R. RStudio, Boston, MA. www.rstudio.com

Reshef L, Koren O, Loya Y, Zilber-Rosenberg I, Rosenberg E (2006) The coral probiotic hypothesis. Environ Microbiol 8:2068-2073

Riegl B, Purkis SJ (2012) Coral reefs of the gulf: adaptation to environmental extremes. Springer, Dordrecht

Roder C, Bayer T, Aranda M, Kruse M, Voolstra CR (2015) Microbiome structure of the fungid coral Ctenactis echinata aligns with environmental differences. Mol Ecol 24:13

Rodolfo-Metalpa R, Houlbrèque F, Tambutté É, Boisson F, Baggini C, Patti FP, Jeffree R, Fine M, Foggo A, Gattuso J-P, HallSpencer JM (2011) Coral and mollusc resistance to ocean acidification adversely affected by warming. Nat Clim Change $1: 308$

Rohwer F, Seguritan V, Azam F, Knowlton N (2002) Diversity and distribution of coral-associated bacteria. Mar Ecol Prog Ser 13:1-10

Salter SJ, Cox MJ, Turek EM, Calus ST, Cookson WO, Moffatt MF, Turner P, Parkhill J, Loman NJ, Walker AW (2014) Reagent and laboratory contamination can critically impact sequence-based microbiome analyses. BMC Biol 12(1):87

Schloss PD, Westcott SL, Ryabin T, Hall JR, Hartmann M, Hollister EB, Lesniewski RA, Oakley BB, Parks DH, Robinson CJ, Sahl JW, Stres B, Thallinger GG, Van Horn DJ, Weber CF (2009) Introducing mothur: open-source, platform-independent, community-supported software for describing and comparing microbial communities. Appl Environ Microbiol 75(23):7537-7541

Silverstein RN, Cunning R, Baker AC (2017) Tenacious D: Symbiodinium in clade $\mathrm{D}$ remain in reef corals at both high and low temperature extremes despite impairment. J Exp Bio 220:1192-1196

Stat M, Morris E, Gates RD (2008) Functional diversity in coraldinoflagellate symbiosis. Proc Natl Acad Sci USA 105:9256-9261

Strahl J, Stolz I, Uthicke S, Vogel N, Noonan SHC, Fabricius KE (2015) Physiological and ecological performance differs in four coral taxa at a volcanic carbon dioxide seep. Comp Biochem Physiol A Physiol 184:179-186

Suggett DJ, Warner ME, Leggat W (2017) Symbiotic dinoflagellate functional diversity mediates coral survival under ecological crisis. Trends in Ecol Evol 32:735-745

Suzuki G, Yamashita H, Kai S, Hayashibara T, Suzuki K, Iehisa Y, Okada W, Ando W, Komori T (2013) Early uptake of specific symbionts enhances the post-settlement survival of Acropora corals. Mar Ecol Prog Ser 494:149-158

Toller WW, Rowan R, Knowlton N (2001) Zooxanthellae of the Montastraea annularis species complex: patterns of distribution of four taxa of Symbiodinium on different reefs and across depths. Bio Bull 201:348-359

Torda G, Donelson JM, Aranda M, Barshis DJ, Bay L, Berumen ML, Bourne DG, Cantin N, Foret S, Matz M, Miller DJ, Moya A, Putnam HM, Ravasi T, van Oppen MJH, Thurber RV, VidalDupiol J, Voolstra CR, Watson S-A, Whitelaw E, Willis BL, Munday PL (2017) Rapid adaptive responses to climate change in corals. Nat Clim Change 7:627

Tout J, Siboni N, Messer LF, Garren M, Stocker R, Webster NS, Ralph PJ, Seymour JR (2015) Increased seawater temperature increases the abundance and alters the structure of natural Vibrio populations associated with the coral Pocillopora damicornis. Front Microbio 6:432

Vega Thurber R, Willner-Hall D, Rodriguez-Mueller B, Desnues C, Edwards RA, Angly F, Dinsdale E, Kelly L, Rohwer F (2009) Metagenomic analysis of stressed coral holobionts. Environ Microbiol 11:2148-2163 
Vega Thurber RL, Burkepile DE, Fuchs C, Shantz AA, McMinds R, Zaneveld JR (2014) Chronic nutrient enrichment increases prevalence and severity of coral disease and bleaching. Global Change Biol 20:544-554

Yokouchi H, Fukuoka Y, Mukoyama D, Calugay R, Takeyama H, Matsunaga $\mathrm{T}$ (2006) Whole-metagenome amplification of a microbial community associated with scleractinian coral by multiple displacement amplification using $\$ 29$ polymerase. Environ Micobio 8(7):1155-1163

Zaneveld JR, McMinds R, Thurber RV (2017) Stress and stability: applying the Anna Karenina principle to animal microbiomes. Nature Microbio 2(9):17121

Ziegler M, Roik A, Porter A, Zubier K, Mudarris MS, Ormond R, Voolstra CR (2016) Coral microbial community dynamics in response to anthropogenic impacts near a major city in the central Red Sea. Marine Poll Bull 105:629-640

Ziegler M, Seneca FO, Yum LK, Palumbi SR, Voolstra CR (2017) Bacterial community dynamics are linked to patterns of coral heat tolerance. Nat Comm 8:14213

Ziegler M, Grupstra CG, Barreto MM, Eaton M, BaOmar J, Zubier K, Al-Sofyani AA, Turki AJ, Ormond R, Voolstra CR (2019) Coral bacterial community structure responds to environmental change in a host-specific manner. Nature Comm 10(1):3092 